\title{
UJI KANDUNGAN KIMIA EKSTRAK BUAH KARAMUNTING (Melastoma malabathricum) SEBAGAI UPAYA MENGHASILKAN BAHAN PEWARNA ALAMI TEKSTIL
}

\author{
Jerni Larahmah"1), Hotni Arista Harahap ${ }^{1)}$, Ledy Yolanda Pasaribu'), Melvariani Syari \\ Batubara1). \\ 1) Prodi Pendidikan Biologi, FKIP, Universitas Muhammadiyah Tapanuli Selatan \\ e-mail: melvarianisyari@um-tapsel.ac.id.
}

\begin{abstract}
The goal to be achieved is to find alternative natural textile dyes using caramunting fruit extract (Melastoma malabathricum) as a substitute material. The method that will be used is the experimental method to determine the ability of caramunting fruit extract (Melastoma malabathricum) as a natural dye of various types of textile materials. Measurements are made once at the same time. The activities carried out were the making of caramunting fruit extract (Melastoma malabathricum), chemical content testing of caramunting fruit extract (Melastoma malabathricum), and coloring of several types of fabric. The results of this study indicate that alternative natural textile dyes using caramunting fruit extract (Melastoma malabathricum) as a substitute material. Where from the results of the test of the chemical content of caramunting fruit extracts the highest were flavonoids, tannins and polyphenols, while the lowest chemical content was alkaloids. From the test results of caramunting fruit extract dyes on various types of Asianteks fabric is the type with the best quality of fabric color with a long time absorption of fabric dyes is 30 minutes.
\end{abstract}

Keywords: Caramunting fruit, Melastoma malabathricum, natural dye, Textile

\begin{abstract}
Abstrak
Tujuan yang ingin dicapai adalah untuk mencari alternatif bahan pewarna alami tekstil dengan menggunakan ekstrak buah karamunting (Melastoma malabathricum) sebagai bahan penggantinya. Metode yang akan dipakai adalah metode eksperimen untuk mengetahui kemampuan ekstrak buah karamunting (Melastoma malabathricum) sebagai pewarna alami berbagai jenis bahan tekstil. Pengukuran dilakukan satu kali dalam waktu yang bersamaan. Kegiatan yang dilaksanakan adalah pembuatan ekstrak buah karamunting (Melastoma malabathricum), uji kandungan kimia ekstrak buah karamunting (Melastoma malabathricum), dan pewarnaan beberapa jenis kain. Hasil penelitian ini menunjukkan bahwa alternatif bahan pewarna alami tekstil dengan menggunakan ekstrak buah karamunting (Melastoma malabathricum) sebagai bahan penggantinya. Dimana dari hasil uji kandungan kimia ekstrak buah karamunting yang tertinggi adalah zat flavonoid, tanin, dan polifenol, sedangkan kandungan kimia yang terendah adalah zat alkaloid. Dari hasil uji zat warna ekstrak buah karamunting pada berbagai jenis kain Asianteks adalah jenis yang kualitas warna kainnya paling baik dengan lama waktu penyerapan zat warna kain adalah 30 menit.
\end{abstract}

Kata Kunci: Buah karamunting, Melastoma malabathricum, Pewarna alami, tekstil

\section{PENDAHULUAN}

Karamunting sangat digemari oleh anak-anak sewaktu kecil, dan karamunting biasa tumbuh di sekitar hutan atau di pinggir rumah dengan tinggi $\pm 1 \mathrm{~m}$ bahkan ada setinggi orang dewasa di padang terbuka. Dengan rasa gurih dan manis tak lepas dari ecapan lidah ketika menikmatinya. Mungkin sekarang, sudah jarang terlihat karena maraknya lahan perumahan dan pertanian holtikultura yang 
menggantikannya.

Ada istilah tak perlu dirawat, tapi tetap tumbuh dan berkembang serta menghasilkan bunga yang indah dan buah berwarna ungu dari kelopaknya. Kedengarannya agak mustahil untuk diolah, dikemas atau dibuat sebagai bahan pewarna alami baik sebagai pewarna makanan atau pewarna tekstil, tapi semua mungkin saja terjadi, asal ada keinginan kuat untuk berpikir mengolahnya dari biasa menjadi sesuatu yang bernilai tambah.

Secara ekonomis, biaya yang dikeluarkan atau dibutuhkan minim untuk mengolahnya. Penelitian ini untuk mengkaji peran karamunting (Melastoma malabathricum) terutama buahnya dari sesuatu yang tidak akan bermanfaat bagi orang banyak menjadi bermanfaat yang dapat teruji secara ilmiah dan bernilai secara ekonomis.

Maraknya industri pangan dan tekstil yang ada saat ini tidak diimbangi dengan kenaikan kualitas produk yang dihasilkan serta tingkat keamanan bahan yang digunakan. Dari pengamatan fitokimia ekstrak buah karamunting mengandung phenol, flavonoid, dan antosianin. Pembuatan ekstrak dilakukan dengan cara maserasi (Jumiati, 2017)

\section{METODE PENELITIAN}

Penelitian ini termasuk dalam penelitian eksperimen untuk mengetahui kemampuan ekstrak buah karamunting (Melastoma malabathricum) sebagai pewarna alami berbagai jenis bahan tekstil. Pengukuran dilakukan satu kali dalam waktu yang bersamaan.

Bahan uji yang digunakan dalam penelitian ini adalah buah karamunting (Melastoma malabathricum) yang diperoleh dari desa Simarsayang, Tapanuli Selatan, Sumatera Utara. Pemilihan buah karamunting (Melastoma malabathricum) yang berkualitas baik, kriteria buah karamunting yang berkualitas adalah diambil langsung dari pohonnya, buah tidak busuk dan berwarna ungu segar, dan buah yang dipetik adalah buah yang matang.

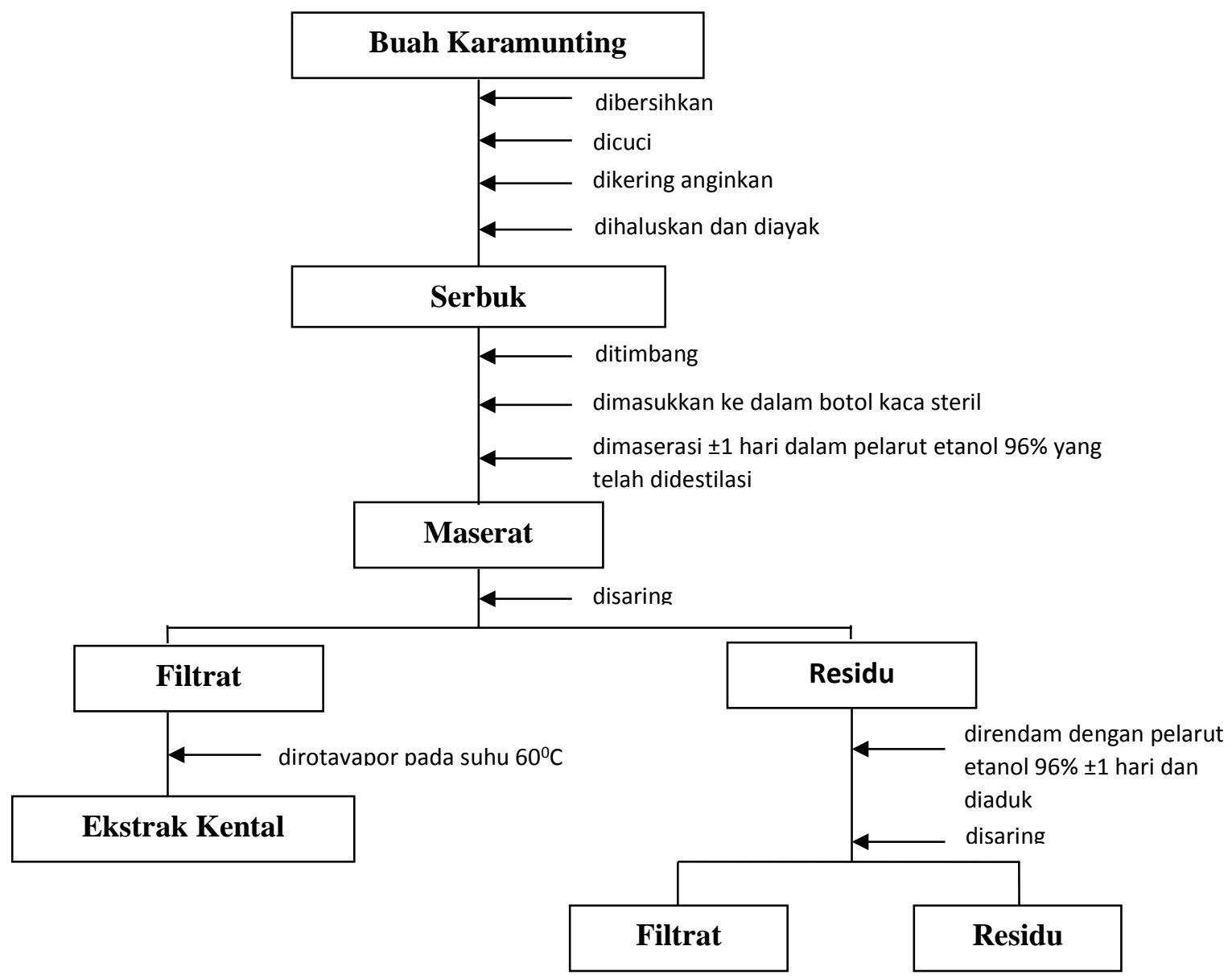

\section{Gambar 1. Pembuatan Ekstrak Buah Karamunting (Melastoma malabathricum)}




\section{Uji Kandungan Kimia Ekstrak Buah Karamunting (Melastoma malabathricum)}

a. Uji Zat Fenolik

$1 \mathrm{~g} \mathrm{FeCl}_{3}+100 \mathrm{ml}$ akuades

b. Uji Zat Flavonoid

$15 \mathrm{~g} \mathrm{Mg}_{(\mathrm{s})}+\mathrm{HCl}_{(\mathrm{p})}+250 \mathrm{ml} \mathrm{NH}_{4} \mathrm{OH}_{(\mathrm{p})}$

c. Uji Zat Alkaloid

- Pereaksi Wagner

2 g KI + 1,27 g Iodium + $100 \mathrm{ml}$ akuades

- Pereaksi Meyer

$1,596 \mathrm{~g} \mathrm{HgCl}_{2}+5 \mathrm{~g} \mathrm{KI}+100 \mathrm{ml}$ akuades

- Pereaksi Dragendorff

8 g Bismut Nitrat $+20 \mathrm{ml} \mathrm{HNO}_{3}+27,2 \mathrm{~g} \mathrm{KI}+80 \mathrm{ml}$ akuades

d. Uji Zat Steroid

Pereaksi Lieberman-Burchad

$\mathrm{H}_{2} \mathrm{SO}_{4}(\mathrm{p})+\mathrm{CH}_{3} \mathrm{COOH}$ an-hidrid dengan perbandingan $1: 20$, v/v)

\section{Pewarnaan}

Langkah awal dalam pewarnaan adalah melarutkan zat pewarna alami yaitu ekstrak buah karamunting (Melastoma malabathricum) yang hendak digunakan menggunakan air atau medium lain yang dapat melarutkan zat warna tersebut, kemudian beberapa jenis kain kain dimasukkan ke dalam larutan zat pewarna alami tersebut atau dengan dicolet dengan larutan tersebut sehingga terjadi penyerapan zat ke dalam serat

\section{HASIL DAN PEMBAHASAN}

Dilakukan pengujian kandungan zat kimia ekstrak etanol buah karamunting (Melastoma malabathricum) menggunakan Uji Zat Fenolik, Uji Zat Flavonoid, Uji Zat Alkaloid, dan Uji Zat Steroid.

Tabel 1. Hasil Uji Kandungan Kimia Ekstrak Buah Karamunting

\begin{tabular}{|c|c|}
\hline Zat & Hasil \\
\hline Alkaloid & Positif $(+)$ \\
\hline Steroida \& Minyak Atsiri & Positif $(+++)$ \\
\hline Saponin & Positif $(++)$ \\
\hline Flavonoida & Positif $(+++)$ \\
\hline Tanin & Positif $(+++)$ \\
\hline Polifenol & Positif $(+++)$ \\
\hline
\end{tabular}

Keterangan : (+) : ditemukan dalam kandungan sangat rendah ;

$(++)$ : ditemukan dalam kandungan rendah ;

$(+++)$ : ditemukan dalam kandungan tinggi

Dari Tabel 1. terlihat bahwa kandungan kimia ekstrak buah karamunting yang paling tinggi didapatkan dari zat flavonoida, tanin, polifenol dan steroida \& minyak atsiri, sedangkan zat alkaloid didapatkan dalam kandungan sangat rendah. Diantara 6 macam zat kimia ekstrak buah karamunting yang didapatkan tersebut, kemungkinan yang dapat menjadi bahan pewarna alami tekstil adalah zat flavonoida dan tannin.

Senyawa flavonoid pada umumnya terdapat pada tumbuhan tinggi yang merupakan hasil metabolisme yang terdistribusi ke seluruh jaringan tumbuhan, seperti terkandung dalam biji, buah, kulit batang, akar dan getah dari tumbuhan, disamping itu juga terdapat pada beberapa jenis serangga. Senyawa flavonoid ini pada umumnya memberikan warna yang cantik 
dan menarik, warna yang cantik ini berfungsi sebagai penarik serangga dan hewan dalam penyerbukan dan penyebaran biji tumbuhan. Disamping itu senyawa flavonoid yang terkandung dalam bunga, buah, daun, dan akar tumbuhan juga bersifat racun, yang berfungsi untuk melindungi tumbuhan dari serangga dan binatang hama, serta tumbuhan gulma (Harborne, 1987).
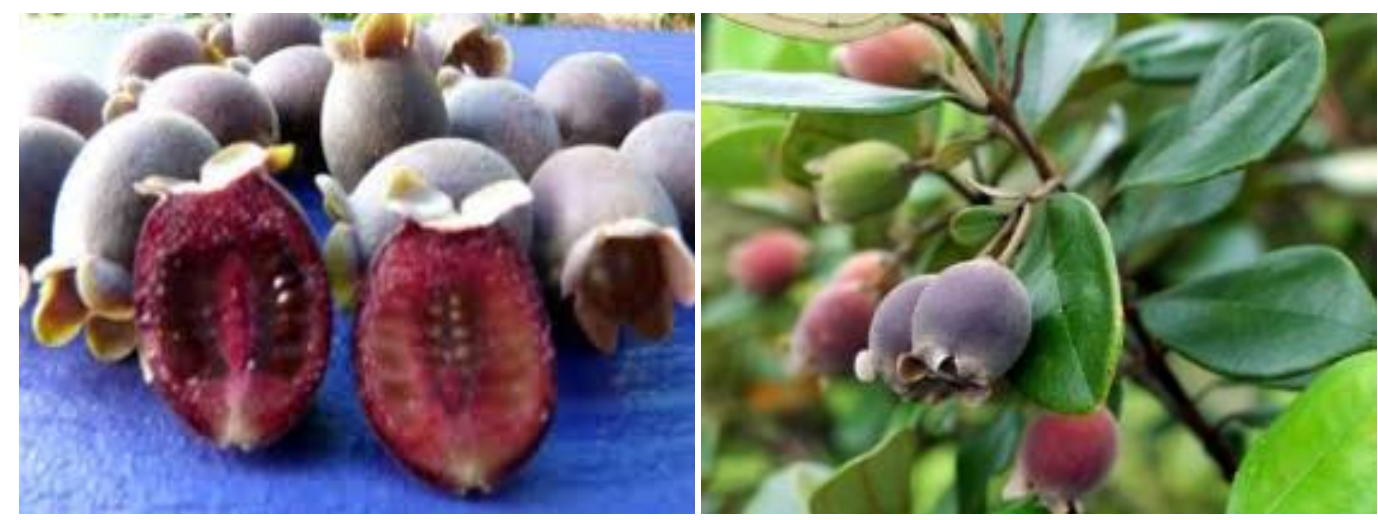

Gambar 2. Buah dan Tanaman Karamunting (Melastoma malabathricum)

Tanin merupakan senyawa organik yang terdiri dari campuran senyawa polifenol kompleks. Tanin tersebar dalam setiap tanaman yang berbatang. Tanin berada dalam jumlah tertentu, biasanya berada pada bagian yang spesifik tanaman seperti daun, buah, akar dan batang. Tanin merupakan senyawa kompleks, biasanya merupakan campuran polifenol yang sukar untuk dipisahkan karena tidak dalam bentuk kristal. Tanin biasanya berupa senyawa amorf, higroskopis, berwarna coklat kuning yang larut dalam organik yang polar (Robert, 1997).

Tabel 2. Hasil Uji Zat Warna Ekstrak Buah Karamunting pada Kain

\begin{tabular}{|l|c|l|}
\hline Jenis Kain & $\begin{array}{c}\text { Lama Waktu Penyerapan Zat Warna } \\
\text { (menit) }\end{array}$ & Kualitas Warna Kain \\
\hline Trikote & 30 & Positif $(+)$ \\
\hline Asianteks & 45 & Positif $(+++)$ \\
\hline Rosella & 60 & Positif $(++)$ \\
\hline Roberto & $>24$ Jam & Negatif $(-)$ \\
\hline
\end{tabular}

Keterangan : (-) : kurang baik ; $(+)$ : cukup baik ; $(++)$ : baik ; (+++) : sangat baik

Dari Tabel 2. terlihat bahwa lama waktu penyerapan zat warna dari ekstrak buah karamunting yang paling baik adalah pada jenis kain trikote yaitu sekitar 30 menit, sedangkan jenis kain roberto adalah yang paling tidak baik dalam penyerapan zat warna karena setelah lebih dari 24 jam tidak dapat menyerap zat warna dari ekstrak buah karamunting. Diantara 4 jenis kain yang diuji tersebut yang paling baik kualitas warna kainnya adalah kain asianteks, hal ini disebabkan karena jenis kain asianteks adalah kain yang bahan baku pembuatannya dari kapas.

Menurut Seman (2007) ditinjau dari proses pewarnaannya, pewarna kain pada zaman dahulu dibuat dari bahan-bahan yang bersifat alami. Ada 6 warna utama kain yang dibuat dari zat pewarna alami antara lain : Kuning, bahan pembuatannya adalah kunyit atau temulawak; Merah, bahan pembuatannya adalah gambir, buah mengkudu, cabai merah, atau kesumba; Hijau, bahan pembuatannya adalah daun pudak atau jahe; Hitam, bahan pembuatannya adalah kebuau atau uar; Ungu, bahan-bahan pembuatannya adalah biji buah gandaria; Coklat, bahan pembuatannya adalah uar atau disebut juga kulit buah rambutan. Supaya warna-warnanya menjadi lebih tua, lebih muda, dan supaya tahan lebih lama bahan pewarna tersebut dicampur 
dengan rempah-rempah lain seperti garam, jintan, lada, pala, cengkeh, jeruk nipis, kapur, tawas, cuka, atau terasi.

\section{Gambar 3. Hasil Uji Pewarnaan Beberapa Jenis Kain pada Ekstrak Buah Karamunting}

Menurut Winarsih (2015) langkah awal dalam pewarnaan adalah melarutkan zat pewarna yang hendak digunakan menggunakan air atau medium lain yang dapat melarutkan zat warna tersebut, kemudian kain yang telah dijahit dimasukkan ke dalam larutan zat pewarna atau dengan dicolet dengan larutan tersebut sehingga terjadi penyerapan zat ke dalam serat. Ada tiga cara pewarnaan kain, yaitu: pencelupan, pencoletan, dan pencelupan sekaligus pencoletan.

\section{KESIMPULAN}

Kesimpulan dari penelitian ini adalah alternatif bahan pewarna alami tekstil dengan menggunakan ekstrak buah karamunting (Melastoma malabathricum) sebagai bahan penggantinya. Dimana dari hasil uji kandungan kimia ekstrak buah karamunting yang tertinggi adalah zat flavonoid, tanin, dan polifenol, sedangkan kandungan kimia yang terendah adalah zat alkaloid. Dari hasil uji zat warna ekstrak buah karamunting pada berbagai jenis kain Asianteks adalah jenis yang kualitas warna kainnya paling baik dengan lama waktu penyerapan zat warna kain adalah 30 menit.

\section{UCAPAN TERIMA KASIH}

Penelitian ini didanai oleh Direktorat Jenderal Pembelajaran dan Kemahasiswaan Kementerian Riset, Teknologi dan Pendidikan Tinggi. Para peneliti mengekspresikan apresiasi kepada Universitas Muhammadiyah Tapanuli Selatan (UMTS) untuk bantuan teknisnya.

\section{DAFTAR PUSTAKA}

Chairul, M. Harapini, dan Y. Daryati. 1996. Pengaruh Ekstrak Kencur (Kaempferia galanga L. ) Terhadap Kehamilan Mencit Putih (Mus musculus). Seminar Nasional Indonesia IV. Jakarta ; Lab. Treub Puslitbang Biologi LIPI, Bogor dan Fakultas Farmasi Universitas 17 Agustus 1945.

Darmawati, I. A. P., G. Wijana, A. A. M. Astiningsih, I. A. Mayun dan N. L. M. Pradnyawathi. 2016. Identifikasi dan karakterisasi Tanaman Pewarna Alam Tenun Pegringsingan Desa Tenganan. Agrotrop 6 (1) : 10-18.

Harborne, J. B. 1987. Metode Fitokimia. Cetakan kedua. Bandung ; Penerbit ITB

Jumiati, E., Mardhiana, I. M. Abdiani. 2017. Pemanfaatan Buah Karamunting Sebagai Pewarna Alami Makanan. Agrifor 16 (2). 
Kelana, T. B., 2012. Isolasi, Elusidasi Struktur Dan Uji “Brine Shrimp” Kandungan Kimia Utama Daun Ficus deltoideus JACIC. VAR Bilobata. Tesis. Padang ; Program Pasca Sarjana Universitas Andalas

Kholis, N. 2016. Kain Tradisional Sasirangan “Irma Sasirangan” Kampung Melayu Kalimantan Selatan. Skripsi. Universitas Negeri Yogyakarta.

Pirnanda, D., H. Sumantri dan R.B. Prasetyo. 2016. Panduan Lapangan Pengenalan Jenis Tumbuhan di Kawasan Ekosistem Hutan dataran Rendah, Sumatera Selatan. Biodiversity and Climate Cange Project.

Robert, H.D. 1997. Aloe Vera: A Scientific Approach. Vantage Press, Inc. New York.

Seman, S. 2007. Sasirangan Kain Khas Banjar. Kalimantan Selatan: Lembaga Pengkajian dan Pelestarian Budaya Banjar.

Winarsih, T. 2015. Kain Sasirangan dan Asal-usul Batik di Indonesia: CV.Sabdo Pinilih. 